\title{
How mutant p53 empowers Foxh1 fostering leukaemogenesis?
}

\author{
Ivano Amelio (1)
}

This year the biomedical research community is celebrating the 40th anniversary of the discovery of the most frequently mutated gene across all human cancer ${ }^{1}$. p53 was firstly identified in 1979; for a decade, its function was associated with its oncogenic properties, leading to the conclusion that p53 was a powerful oncogene ${ }^{2-4}$. Only later, the confusion was clarified: most of the researchers were unaware that they were in fact studying its mutant forms $^{5,6}$. 40 years later, whether p53 mutants are effectively functioning as oncogenes and whether their gain-offunction effects are contributing to the pathogenesis of cancer remains largely controversial $^{7-9}$ (Fig. 1). But how does mutant p53 gain its oncogenic properties? Scott Lowe's group recently reported important observations in support of a major contribution of p53 mutants to myeloid leukaemia pathogenesis ${ }^{10}$.

In acute myeloid leukaemia (AML) TP53 mutations are mainly associated with the subtype known as complex karyotype AML (CK-AML). CK-AML is a lethal disease (less than 2\%, 5-year survival) characterised by the presence of several cytogenetic abnormalities. Lowe and colleagues' work formally demonstrates that expression of $\mathrm{p} 53^{\mathrm{R} 172 \mathrm{H}}$ (the mouse orthologue of the human $\mathrm{R} 175 \mathrm{H}$ mutation) accelerates the onset of haematological malignancies beyond the effects of p53 deficiency ${ }^{10}$. Consistent with what has previously been reported, mice harbouring $\mathrm{p} 53^{\mathrm{R} 172 \mathrm{H}}$ succumb from thymic lymphomas faster than mice completely lacking p53 expression. To assess the impact of $\mathrm{p} 53^{\mathrm{R} 172 \mathrm{H}}$ in the clinically relevant context of AML, the authors transplanted bone marrow cells from Mx1-Cre; $\mathrm{p} 53^{\mathrm{R} 172 \mathrm{H} / \mathrm{F}}$ and $M x 1-\mathrm{Cre} ; \mathrm{p} 53^{\mathrm{F} / \mathrm{F}}$ mice into thymectomized recipient mice. The $\mathrm{p} 53^{\mathrm{R} 172 \mathrm{H} /-}$ mice succumbed to the disease faster than their p53-null counterparts. Importantly, depletion of $\mathrm{p} 53^{\mathrm{R} 172}$ by an inducible shRNA system in AML

\footnotetext{
Correspondence: Ivano Amelio (ia348@mrc-tox.cam.ac.uk)

${ }^{1}$ Medical Research Council, Toxicology Unit, Department of Pathology,

University of Cambridge, Tennis Court Road, Cambridge CB2 1QP, UK
}

cells led to differentiation and apoptosis, indicating that AML cells expressing $\mathrm{p} 53^{\mathrm{R} 172 \mathrm{H}}$ acquire a molecular dependency on mutant $\mathrm{p} 53$. Hence, $\mathrm{p} 53^{\mathrm{R} 172}$ contributes to a differentiation block that sustains leukemogenesis ${ }^{10}$. This set of data therefore supports a gain-of-function effect of $\mathrm{p} 53^{\mathrm{R} 172}$ in an AML setting.

Lowe's team observed that the adult bone marrow cells from $\mathrm{p} 53^{\mathrm{R} 172 \mathrm{H} / \Delta}$ mice have significantly higher replating capacity compared to cells from p $53^{- \text {-null }}$ mice in a serial replating experiment performed with limiting dilution cultures in methylcellulose medium. Consistent with these findings, competitive transplantation studies using $\mathrm{p} 53^{\mathrm{WT} / \mathrm{WT}}, \mathrm{p} 53^{\Delta / \Delta}$, and $\mathrm{p} 53^{\mathrm{R} 172 \mathrm{H} / \Delta}$ bone marrow cells demonstrated that $\mathrm{p} 53^{\mathrm{R} 172 \mathrm{H} / \Delta}$ cells outcompeted wildtype cells to a greater extent than $\mathrm{p} 53^{\Delta / \Delta}$ cells. These observations establish a role for $\mathrm{p} 53^{\mathrm{R} 172 \mathrm{H}}$ in a premalignant setting in sustaining pathologic self-renewal in adult hematopoietic cells. Remarkably, the increase in self-renewal capacity was observed in $\mathrm{p} 53^{\mathrm{R} 172 \mathrm{H} / \Delta}$ but not $\mathrm{p} 53^{\mathrm{R} 172 \mathrm{H} / \mathrm{WT}}$ cells, suggesting that loss of the residual WT allele is a prerequisite ${ }^{10}$. While overall these data support a $\mathrm{p} 53^{\mathrm{R} 172 \mathrm{H}}$ gain-of-function effect as they contradict the long-lasting hypothesis of a dominant negative effect of p53 mutants on wt p53 (and possibly other p53 family members). This highlights the complexity of the p53 mutant gain-of-function effects and the corresponding difficulties in unifying diverse observations.

From a mechanistic standpoint, the authors showed that $\mathrm{p} 53^{\mathrm{R} 172 \mathrm{H}}$ promotes expression of the Foxh1 transcriptional factor, thus supporting a transcriptional reprogramming that sustains the enhanced self-renewal phenotype of leukaemic cells. This transcriptional signature was also found to be correlated with p53 mutant status in human CK-AML. Foxh1 expression was proved to be necessary and sufficient to sustain the $\mathrm{p} 53^{\mathrm{R} 172 \mathrm{H}}$ dependent phenotype. Enforced or reduced expression of Foxh1 affected hematopoietic cell differentiation and self-

(c) Open Access This article is licensed under a Creative Commons Attribution 4.0 International License, which permits use, sharing, adaptation, distribution and reproduction in any medium or format, as long as you give appropriate credit to the original author(s) and the source, provide a link to the Creative Commons license, and indicate if changes were made. The images or other third party material in this article are included in the article's Creative Commons license, unless indicated otherwise in a credit line to the material. If material is not included in the article's Creative Commons license and your intended use is not permitted by statutory regulation or exceeds the permitted use, you will need to obtain permission directly from the copyright holder. To view a copy of this license, visit http://creativecommons.org/licenses/by/4.0/. 

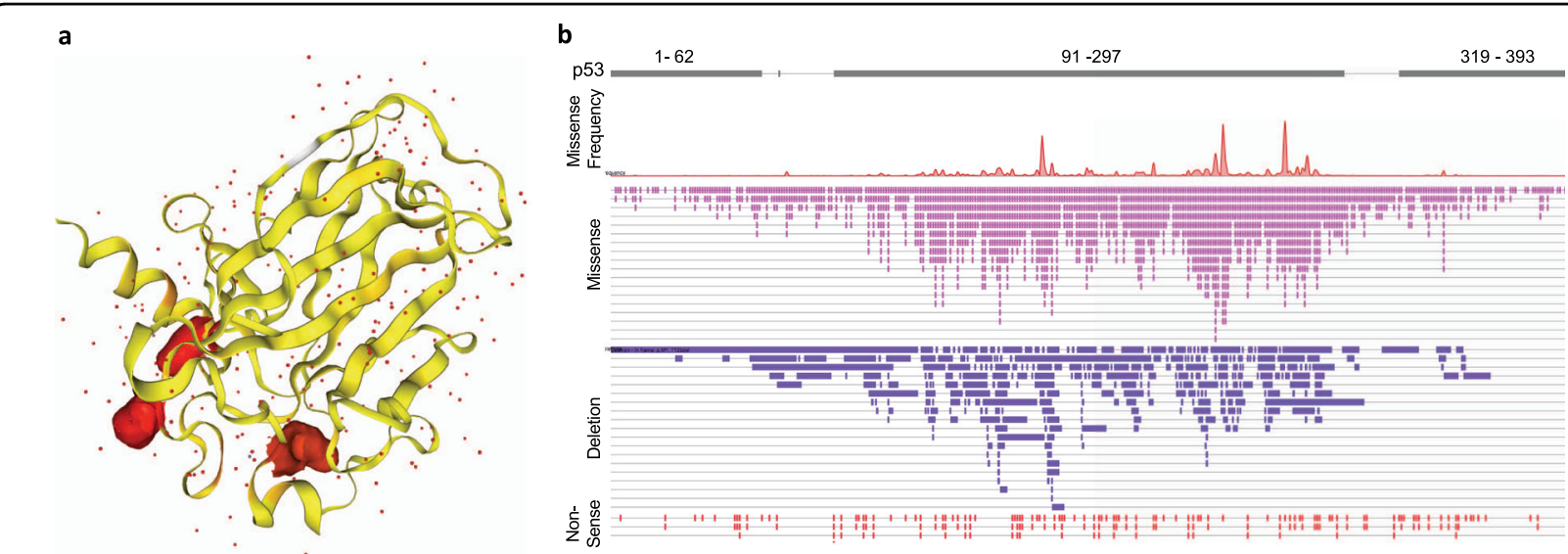

Fig. 1 p53 mutational spectrum. a Structural representation of human p53 core domain with hot spot mutation R273H. b Schematic representation of p53 domains including information on frequencies and types of mutations spanning across the entire human p53 sequence in acute amyloid leukaemia. Red picks indicate frequency of hotspot mutations; pink bars indicate position and type of missense mutations; purple bars indicate position and type of in frame deletions; red bars indicate position and type of nonsense mutations. Highest frequency and variety of mutations is observed in the p53 DNA binding domain. Source: COSMIC mutation database

renewal capacity consistent with the pathological role of the $\mathrm{p} 53^{\mathrm{R} 172 \mathrm{H}}$-Foxh1 axis $^{10}$. Hence, this study demonstrates that, in this specific context, mutant p53 acts as a bona fide oncogene that contributes to the pathogenesis of CK-AML with a mechanism involving Foxh1.

In the wide range of proposed p53 mutant gain-offunction mechanisms and the highly diverse sets of observations related to its oncogenic phenotype, this study establishes proliferative potential and self-renewal capacity as consistent and relevant aspects in the biology of mutant p53 gain-of-function. Cancer cells expressing p53 mutants appear to acquire proliferative benefits that may substantially exceed the advantage conferred by loss of the wild-type endogenous p53. However, this simplistic interpretation of the mutant p53 gain-of-function does not necessarily explain how cancer cells became dependent on mutant p53 expression, a phenomenon highly reproducible across many cancer types and characteristic of several different mutants ${ }^{11}$. A proliferative advantage indeed does not fully justify the addiction that cancer cells display to p53 mutant expression. Despite its important therapeutic implications, the underlining mechanisms associated with p53 mutant dependency therefore remain largely unexplained.

It is also still unclear how mutant p53 is executing its gain-of-function effects. Is the p53 mutant protein capable of specifically controlling molecular signalling or is it randomly altering physiological molecular networks? $\mathrm{p} 53^{\mathrm{R} 172 \mathrm{H}}$ leukaemic cells express high levels of Foxh1, but how this occurs remains to be determined. Several transcriptional factors, including SREBPs and HIF-1 have been shown to be altered in their transcriptional ability by mutant $\mathrm{p} 53^{12-14}$, although it remains unclear how mutant p53 modifies their function. A fascinating unifying hypothesis could be that p53 status influences the global epigenetic landscape thus indirectly influencing the function of many transcriptional factors.

Additional work, and also careful reanalysis of the available data, is still required to assess the individual contribution of gain-of-function and loss-of-function mutant p53 to cancer pathogenesis. For example, it is interesting that loss of genomic integrity related to p53 inactivation is observed both in p53-null and p53 mutant backgrounds ${ }^{12}$. Genomic instability is a hallmark of malignant cancers and is crucially associated with the acquisition of the cellular plasticity that is necessary for evolution of the malignant disease. In assessing the relative contribution of the gain-of-function vs. the loss-offunction mutants, the contribution of any additional p53 mutant property might therefore appear marginal in comparison with the loss of genomic integrity. However, the strong selective pressure that leads to acquisition of missense mutations in the TP53 gene rather than total gene deletion remains a very important argument in support of the relevance of the gain-of-function mutants ${ }^{15}$.

Conflict of interest

The author declares that he has no conflict of interest.

\section{Publisher's note}

Springer Nature remains neutral with regard to jurisdictional claims in published maps and institutional affiliations.

Received: 30 May 2019 Accepted: 11 June 2019

Published online: 24 June 2019 


\section{References}

1. Levine, A. J. Reviewing the future of the P53 field. Cell Death Differ. 25, 1-2 (2018).

2. Linzer, D. I. \& Levine, A. J. Characterization of a 54K dalton cellular SV40 tumor antigen present in SV40-transformed cells and uninfected embryonal carcinoma cells. Cell 17, 43-52 (1979).

3. Lane, D. P. \& Crawford, L. V. T antigen is bound to a host protein in SV40transformed cells. Nature 278, 261-263 (1979).

4. Levine, A. J. The many faces of p53: something for everyone. J. Mol. Cell. Biol. https://doi.org/10.1093/jmcb/mjz026 (2019).

5. Finlay, C. A., Hinds, P. W. \& Levine, A. J. The p53 proto-oncogene can act as a suppressor of transformation. Cell 57, 1083-1093 (1989).

6. Eliyahu, D., Michalovitz, D., Eliyahu, S., Pinhasi-Kimhi, O. \& Oren, M. Wild-type p53 can inhibit oncogene-mediated focus formation. Proc. Natl Acad. Sci. USA 86, 8763-8767 (1989)

7. Kim, M. P. \& Lozano, G. Mutant p53 partners in crime. Cell Death Differ. 25, 161-168 (2018)

8. Kaiser, A. M. \& Attardi, L. D. Deconstructing networks of p53-mediated tumor suppression in vivo. Cell Death Differ. 25, 93-103 (2018).
9. Aubrey, B. J., Kelly, G. L., Janic, A., Herold, M. J. \& Strasser, A. How does p53 induce apoptosis and how does this relate to p53-mediated tumour suppression? Cell Death Differ. 25, 104-113 (2018).

10. Loizou, E. et al. A gain-of-function p53 mutant oncogene promotes cell fate plasticity and myeloid leukemia through the pluripotency factor Foxh1. Cancer Discov. https://doi.org/10.1158/2159-8290.CD-18-1391 (2019).

11. Alexandrova, E. M. et al. Improving survival by exploiting tumour dependence on stabilized mutant p53 for treatment. Nature 523, 352-356 (2015).

12. Amelio, I. et al. p53 mutants cooperate with HIF-1 in transcriptional regulation of extracellular matrix components to promote tumor progression. Proc. Nat Acad. Sci. USA 115, E10869-E10878 (2018).

13. Freed-Pastor, W. A. et al. Mutant p53 disrupts mammary tissue architecture via the mevalonate pathway. Cell 148, 244-258 (2012).

14. Do, P. M. et al. Mutant p53 cooperates with ETS2 to promote etoposide resistance. Genes Dev. 26, 830-845 (2012).

15. Baugh, E. H., Ke, H., Levine, A. J., Bonneau, R. A. \& Chan, C. S. Why are there hotspot mutations in the TP53 gene in human cancers? Cell Death Differ. $\mathbf{2 5}$ 154-160 (2018). 